\title{
Decadal upper ocean temperature variability in the tropical Pacific
}

\author{
Wilco Hazeleger \\ Royal Netherlands Meteorological Institute, De Bilt, The Netherlands \\ Martin Visbeck, Mark Cane, Alicia Karspeck, and Naomi Naik \\ Lamont-Doherty Earth Observatory of Columbia University, Palisades, New York
}

\begin{abstract}
Decadal variability in upper ocean temperature in the Pacific is studied by using observations and results from model experiments. Especially propagation of upper ocean thermal anomalies from the midlatitudes to the tropics is studied as a possible source for decadal equatorial thermocline variability. In the observations, propagation along the subtropical gyre of the North Pacific is clear. However, no propagation into the equatorial region is found. Model experiments with an ocean model forced with observed monthly wind and wind stress anomalies are performed to study the apparent propagation. Distinct propagation of thermal anomalies in the subtropics is found in the model, although the amplitude of the anomalies is small. The anomalies clearly propagate into the tropics, but they do not reach the equatorial region. The small response at the equator to extratropical variability consists of a change in the mean depth of the thermocline. It appears that most variability in the subtropics and tropics is generated by local wind stress anomalies. The results are discussed by using results from a linear shallow water model in which similar features are found.
\end{abstract}

\section{Introduction}

The variability in the upper tropical Pacific has predominately an interannual timescale and is associated with El Niño-Southern Oscillation (ENSO). This phenomenon has been extensively studied and has been explained as a coupled ocean-atmosphere mechanism [Neelin et al., 1998]. The tropical Pacific also exhibits substantial decadal to interdecadal variability [Zhang et al., 1998]. The spatial pattern of this low-frequency variability is similar to the pattern of interannual variability. Along the equator a large sea surface temperature (SST) anomaly stretches from the eastern boundary to the west. At the eastern side of the basin the anomaly extends from the equator toward the midlatitudes. In the western North Pacific an anomaly of the opposite sign is found. The main difference with the classical interannual ENSO pattern is that it extends further away from the equator and has a larger amplitude in the midlatitudes. Around 19421943 and 1976-1977 major shifts have occurred associated with this pattern in the Pacific [Trenberth and Hurrel, 1994; Zhang et al., 1998].

Copyright 2001 by the American Geophysical Union.

Paper number 2000JC000536.

0148-0227/01/2000JC000536\$09.00
Different physical mechanisms have been proposed to explain the origin of low-frequency variability in the tropical Pacific. Gu and Philander [1997] suggested that oceanic advection of subducted anomalies from the extratropics to the tropics sets the timescale of a decadal oscillation. In their conceptual model, anomalies are formed in the winter mixed layer in the midlatitudes. When the mixed layer restratifies, the anomalies subduct and propagate along the westward return flow of the subtropical gyre. The anomalies may reach the tropics, where they can affect the tropical thermocline and generate an unstable air-sea feedback. The atmospheric winds in the midlatitudes respond to the tropical SST variations. These wind anomalies generate anomalies in the oceanic mixed layer that subsequently subduct, and the second half of the cycle starts. A critical link in this mechanism is the advection of the thermal anomalies in the ocean from the midlatitudes toward the tropics which sets the timescale of the oscillation.

The existence of water mass pathways between extratropics and tropics is undisputed. Tritium observations show a connection between the equatorial region and subtropics [Fine et al., 1987]. Also, different model studies indicate water mass pathways from the extratropics to the tropics [Rothstein et al., 1998]. Whether heat or haline anomalies propagate into the tropics is less apparent. The propagation of subducted 
thermal anomalies along the westward return flow of the subtropical gyre is clear from the data [Deser et al., 1996; Zhang et al., 1998], but upon arrival at the western boundary the fate of the anomalies is not clear anymore [Tourre et al., 1999]. Recent model studies indicate that propagation by advection by the mean flow of thermal anomalies toward the equator hardly takes place [Schneider et al., 1999b; Pierce et al., 2000].

An oceanic connection between extratropics and tropics may also be accomplished by propagating planetary waves as suggested by theoretical and modeling studies [Cane and Sarachik, 1977; Lysne et al., 1997; Liu et al., 1999]. Rossby waves can be excited by a variable wind stress forcing at the midlatitudes, propagate to the western boundary, and transfer to the tropics by coastal Kelvin waves. This mechanism will result in a shorter time lag between variability in the extratropics and tropics compared with the lag resulting from the subduction and advection mechanism. Upper ocean temperature anomalies in the 1980s suggest such a small lag.

Other authors stress the importance of an atmospheric "bridge." Decadal variability in the extratropical winds could influence the trades and therefore affect the equatorial thermocline almost instantaneously [Wang and Weisberg, 1998; Barnett et al., 1999]. Pierce et al. [2000] used a coupled ocean-atmosphere model; they found that the impact of the winds dominates, and speculate that changes in the midlatitudes may be important. Finally, low-frequency variability in the tropical Pacific can be a locally coupled phenomenon as indicated by some coupled models [Cane et al., 1995].

The different mechanisms that are proposed for lowfrequency variability in the tropics indicate that there is a lot of uncertainty regarding the origin of that variability. Here we focus on the possible role of the ocean by studying propagation of thermal anomalies from the midlatitudes toward the equator. First, observed heat content variations will be used to see whether thermal anomalies from the midlatitudes propagate into the tropics. These observations include both surface and subsurface thermal variations. Then we will use a numerical ocean model coupled to an atmospheric mixed layer model forced with observed winds to investigate the mechanisms of the observed low-frequency variability. By performing different sensitivity experiments, we deduce by what mechanism thermal anomalies are formed in the extratropics and whether they can reach the tropics. Unlike studies that have been performed with coupled ocean-atmosphere models, we can compare our model results directly with observations. On the other hand, we will not be able to infer whether the simulated variability is part of a coupled ocean-atmosphere phenomenon.

This paper is set up as follows. In section 2 we analyze upper ocean temperature in the 1970 s when propagation from the midlatitudes to the tropics is apparent.
Then in section 3 we present the model and motivate the sensitivity experiments. The results of the different experiments are shown and compared with observations in section 4 , the results are discussed in section 5 by using a simple linear shallow water model, and we conclude in section 6 .

\section{Observed Upper Ocean Variability}

Thermal anomalies that are created at the sea surface by anomalous heat fluxes in the midlatitudes can subduct and propagate southwestward along the gyre circulation while shielded from the sea surface [Deser et al., 1996]. Thus SST and thermocline variations can be decoupled in the westward return flow of the subtropical gyre. Therefore surface and subsurface data must be used to study the propagation of thermal anomalies which propagate from the extratropics to the tropics. Here we analyze upper ocean heat content (the integral of temperature with depth, here 0-400 m) derived from expendable bathythermograph (XBT) data from 1955 to 1998 [White, 1995]. These data were used by Tourre et al., [1999] to analyze interdecadal variability in the North Pacific. Using the complex emperical orthogonal function technique, they found an interdecadal mode of variability with a timescale of $20-25$ years. The mode consists of a growing phase during which anomalies are formed in the western and central North Pacific (along $40^{\circ} \mathrm{N}$ ). After about 4 years, the anomaly turns southwestward at $150^{\circ} \mathrm{W}$ and propagates along the westward return flow of the subtropical gyre. When arriving at the western boundary around $15^{\circ} \mathrm{N}$, the anomaly propagates neither to the north nor to the south but dissipates away at the western boundary. Similar propagation of subsurface temperature anomalies is presented by Zhang and Liu [1999]. Zhang et al. [1998] and Zhang and Liu [1999] argue that these anomalies propagate into the equatorial region and affect the equatorial thermocline.

The statistical analysis of Tourre et al. [1999] shows one full period of the interdecadal cycle. Here we took a different approach and present snapshots of the lowpass-filtered anomalies themselves during half a period of the cycle rather than the reconstructed anomalies from the statistical analysis.

The clearest event starts in the late 1960s. At that time a warm anomaly forms in the upper layers of the central North Pacific (Plate 1a). Plate 1 This anomaly is accompanied by a decrease in the westerly winds that created the warm anomaly owing to a decrease in the outgoing surface heat fluxes. The anomaly strengthens in the early 1970s and two maxima are found (Plate 1b). One maximum covers the Kuroshio region. The other maximum is found in the center of the basin at $40^{\circ} \mathrm{N}$, $150^{\circ} \mathrm{W}$. In the early 1970 s this anomaly turns southwestward and follows the gyre circulation, propagating to the west in 1973, 1974, and 1975 (Plates 1c and 1d). 
a

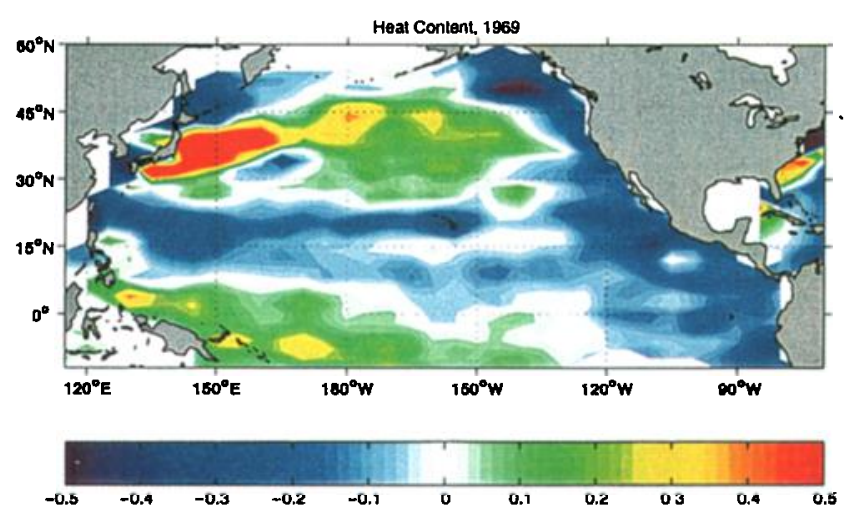

$\mathrm{C}$
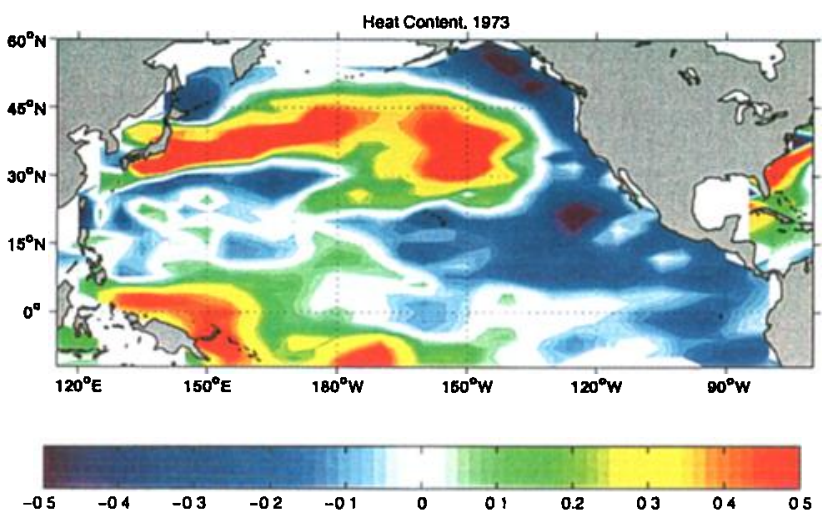

e
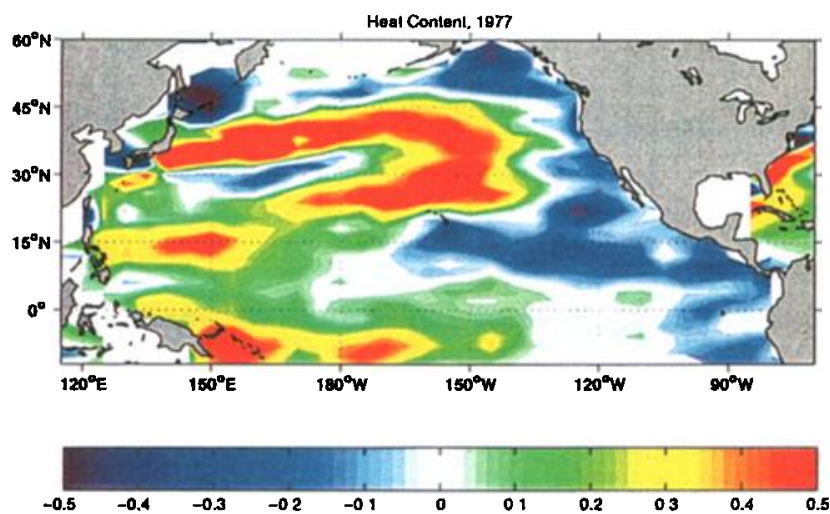

b

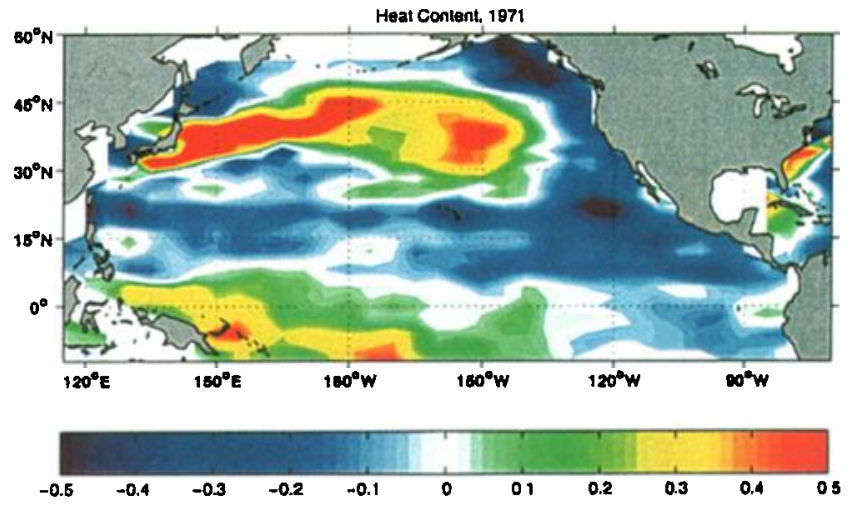

d

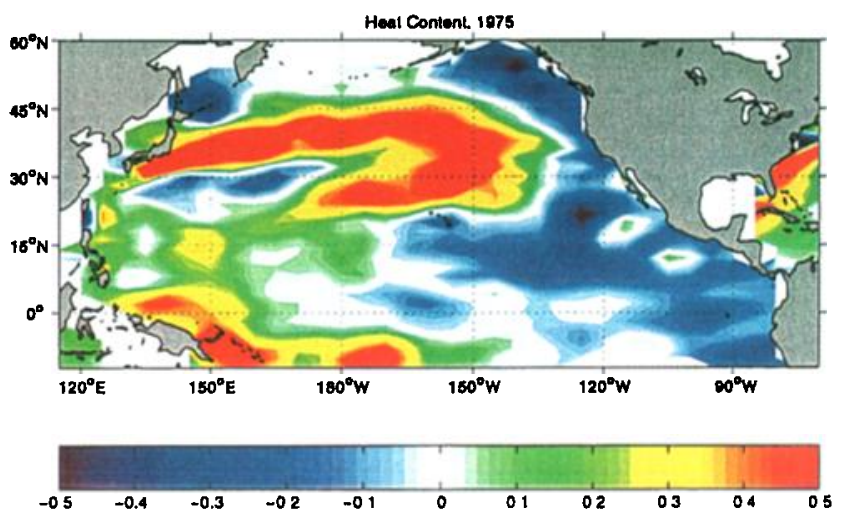

$\mathrm{f}$

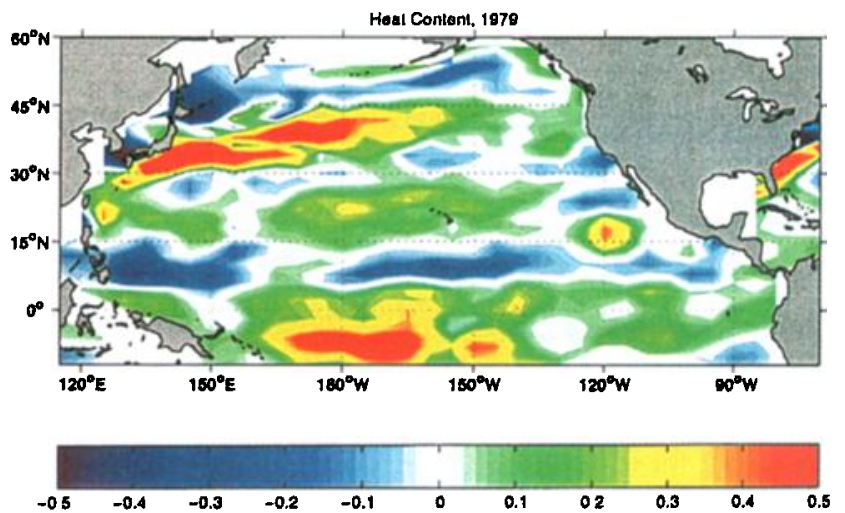

Plate 1. Snapshots of low-pass-filtered upper ocean temperature anomalies (averaged temperature anomaly over upper $400 \mathrm{~m}$ ) in (a) 1969, (b) 1971, (c) 1973, (d) 1975, (e) 1977, and (f) 1979. Anomalies have been low-pass filtered with a Parzen window with a width of 4 years. 
This corresponds to the subduction and subsequent subsurface propagation of the thermal anomaly presented by Deser et al. [1996] and Schneider et al. [1999a]. The subduction takes place in the region $170^{\circ}-145^{\circ} \mathrm{W}, 30^{\circ}-$ $40^{\circ} \mathrm{N}$. In the following years, the anomaly halts around $20^{\circ} \mathrm{N}, 180^{\circ} \mathrm{W}-140^{\circ} \mathrm{W}$ and it slowly fades away (Plates 1e and 1f). Another positive anomaly starts to form in 1974-1975 at $150^{\circ} \mathrm{E}, 15^{\circ} \mathrm{N}$ near the western boundary (Plate 1d). This anomaly seems to be related to the anomaly propagating around the gyre, but the anomalies never connect. The statistical analysis of Tourre et al. [1999] lumps the two positive anomalies together, possibly owing to the stronger low-pass filter that they used. Zhang et al. [1998] and Zhang and Liu [1999] interpret the apparent connection between the anomalies as a verification of the advective path of midlatitude anomalies to the equator. However, the snapshots indicate that the anomalies in the central subtropical Pacific and western tropical Pacific were formed independently. Propagation of the midlatitude anomalies is halted in the central subtropical Pacific where they fade away. Also, in the second, less clear part of the interdecadal cycle that started around 1985, the subduction and initial propagation is clear, but the advection toward the western boundary is hardly visible (not shown).

As is shown here, the evidence for an oceanic bridge for thermal anomalies from the midlatitudes to the equatorial region from data is weak, but the mechanism cannot be ruled out owing to the sparsity of the data and the relatively short data record. Therefore we have performed a number of experiments with a numerical ocean model forced with observed winds to clarify whether propagation toward the tropics can take place. Furthermore, we intend to find out what mechanisms are responsible for generating the observed anomalies in the (sub)tropical Pacific.

\section{Experimental Setup}

\subsection{Models}

For most experiments a primitive equation ocean model is used [see Visbeck et al., 1998; Rodgers et al., 1999; Hazeleger et al., 2001]. The model has a resolution of $2.5^{\circ}$ by $2.5^{\circ}$ in the midlatitudes. In the tropics the resolution in the meridional direction increases toward $0.5^{\circ}$ at the equator. The model has 20 levels in the vertical. The domain spans from $62^{\circ} \mathrm{N}$ to $62^{\circ} \mathrm{S}$ and from $90^{\circ} \mathrm{E}$ to $70^{\circ} \mathrm{W}$. The model includes the Indonesian Throughflow of which the barotropic transport is set at $10 \mathrm{~Sv}$. Furthermore, the model includes a KrausTurner mixed layer scheme and a one and a half layer thermodynamic ice model. An isopycnal thickness mixing scheme is incorporated with a spatially varying eddy diffusivity [Visbeck et al., 1997]. The diffusivity coefficient varies from $150 \mathrm{~m}^{2} \mathrm{~s}^{-1}$ in the interior to $1500 \mathrm{~m}^{2}$ $\mathrm{s}^{-1}$ in the jet regions. The vertical mixing is Richardson number dependent with a background diffusivity of $10^{-4} \mathrm{~m}^{2} \mathrm{~s}^{-1}$. The model uses a total variation diminishing (TVD) scheme for the horizontal advection terms. For time differencing a second-order Lorenz $N$ cycle is used. All boundaries are closed except for the southern boundary of the basin where the temperature and salinity are restored toward observations [Levitus and Boyer 1994; Levitus et al. 1994].

The ocean model is coupled to an atmospheric mixed layer model [Seager et al., 1995] to create the socalled Lamont Ocean Atmospheric mixed layer Model (LOAM) model. In the atmospheric mixed layer the virtual potential temperature and the humidity are computed from a balance between advection, surface fluxes, fluxes at the top of the mixed layer, and radiative fluxes. The surface heat fluxes are determined by familiar bulk transfer formulae. The fluxes at the top of the atmospheric mixed layer are parameterized according to Seager et al. [1995]. Cooling by midlatitude storms is parameterized according to Hazeleger et al. [2001]. Only the wind, wind speed, cloud cover, and shortwave radiation are prescribed. The advantage of this model is that the surface latent heat, sensible heat, and long-wave fluxes are internally generated. This implies that SST signals are not already captured in the heat fluxes, which is the case in hindcasts with prescribed heat fluxes or prescribed air temperatures. The salinity at the surface is restored to climatology [Levitus et al., 1994]. Furthermore, fractional cloudiness and the solar radiation at the sea surface is prescribed (International Satellite Cloud Climatology Project [Bishop and Rossow, 1991]). At the lateral boundaries the potential temperature and the specific humidity at the surface are prescribed [Da Silva et al., 1994].

The LOAM model has been spun up for 40 years with climatological winds, wind speed, and wind stresses $[D a$ Silva et al., 1994]. The upper ocean is in equilibrium after 40 years of spini-up. The mean state of the model solution is realistic. For details on the model and a comparison of model climatology with observations, we refer to Hazeleger et al. [2001].

To identify some basic mechanisms of exchange of mass between the midlatitudes and the tropics, we performed an experiment with a linear shallow water model. The nondimensional equations that are solved are

$$
\begin{aligned}
& \frac{\partial u}{\partial t}-f v+\frac{\partial h}{\partial x}=\tau_{x} \\
& \frac{\partial v}{\partial t}+f u+\frac{\partial h}{\partial y}=\tau_{y} \\
& \frac{\partial h}{\partial t}+\frac{\partial u}{\partial x}+\frac{\partial v}{\partial y}=0
\end{aligned}
$$

where $u$ and $v$ are the zonal and meridional velocity perturbations, $h$ is the layer depth perturbation, and $f$ is the Coriolis parameter; $\tau_{x}$ and $\tau_{y}$ are the zonal and meridional wind stress anomalies. The equations 
have been nondimensionalized with length scale $L=$ $(c / \beta)^{1 / 2}$ and timescale $T=(c \beta)^{-1 / 2}$, where $c=(g H)^{1 / 2}$ is the wave speed, $H$ is the equivalent depth, and $\beta=$ df / dy.

The shallow water system is solved for two vertical standing modes, with speeds $c_{1}=2.98 \mathrm{~m} / \mathrm{s}$ and $c_{2}=$ $1.84 \mathrm{~m} / \mathrm{s}$. These wave speeds are calculated from the observed vertical density profile along the date line [ Levitus et al., 1994] and are assumed to be uniform over the entire domain. The domain of the model captures the Pacific Ocean from $60^{\circ} \mathrm{N}$ to $60^{\circ} \mathrm{S}$ and has realistic coast lines. The linear model calculates monthly thermocline depth anomalies at a resolution of $2^{\circ}$ in the zonal direction and $0.5^{\circ}$ in the meridional direction. The model is solved by using the numerical scheme that is described by Israeli et al. [2000]. The results of this model are compared with those of the LOAM model.

\subsection{Experiments}

After the spin-up, the LOAM model has been forced with observed monthly vector wind and wind speed anomalies from Comprehensive Ocean-Atmosphere Data Set (COADS) (1945-1993 [Da Silva et al., 1994]) on top of the climatological monthly mean winds. This is the control experiment (see Table 1).Table 1

In the first sensitivity experiment the winds were held at their climatological monthly mean values in the tropics and subtropics. In a strip between $30^{\circ} \mathrm{N}$ and $30^{\circ} \mathrm{S}$ (tapered gradually between $28^{\circ}$ and $32^{\circ}$, see Figure 1 ), no anomalies in the surface forcing are applied (experiment MID). Figure 1 This setup ensures that all low-frequency variability in the tropics is of midlatitudinal origin and is generated by oceanic processes alone. In the observations, large anomalies subduct between $170^{\circ} \mathrm{W}$ and $145^{\circ} \mathrm{W}$ and $30^{\circ} \mathrm{N}$ and $40^{\circ} \mathrm{N}$ [Schneider et al., 1999a]. Therefore with this experiment we can test whether the oceanic "bridge" can be accomplished by advection of subducted anomalies from the midlatitudes toward the tropics.

In a second experiment we applied observed anomalies in the atmospheric forcing in a tropical strip between $16^{\circ} \mathrm{N}$ and $16^{\circ} \mathrm{S}$ (gradually tapered between $14^{\circ}$ and $18^{\circ}$ ). In this experiment, all extratropical influ- ences on the tropics by oceanic processes are excluded (experiment TRP).

In a third sensitivity experiment, only anomalies in the wind stress were used (experiment WST). Climatological monthly mean wind speed and vector wind were applied. The surface heat fluxes are determined by a bulk transfer relation. So anomalous surface fluxes can arise from anomalous wind speeds and anomalous air temperatures or humidity. By keeping the wind speeds and vector winds constant, the air-sea temperature and humidity differences remain the only free variables in the bulk transfer relation. In that case, anomalous heat fluxes can only damp SST anomalies. The main way for the atmospheric forcing to create SST anomalies is by Ekman divergence and convergence. With this experiment we investigate by which surface forcing mechanism upper ocean thermal anomalies are formed.

In the last experiment we used the linear model. The model was forced with observed wind stress anomalies (experiment LIN). Just as in experiment MID, no anomalies were applied in a strip between $30^{\circ} \mathrm{N}$ and $30^{\circ} \mathrm{S}$ (tapered to $25^{\circ}$ ).

Some of the model experiments are similar to those performed by Schneider et al. [1999], but here we use a different model configuration. The differences can potentially have a large effect. Schneider et al. used the Hamburg Ocean Primitive Equation model, which is a $z$ coordinate ocean-only model with a horizontal eddy mixing scheme and a closed Indonesian Throughflow. Their model was forced with observed surface fluxes and a relaxation to observed SST and sea surface salinity. The LOAM model incorporates an isopycnal thickness mixing scheme with a varying eddy diffusivity for parameterizing the subgrid-scale eddies. This scheme leads to less spurious mixing than the horizontal mixing scheme which may lead to more long-lived anomalies in the model. Furthermore, we opened the Indonesian Throughflow that regulates the distribution at the equator of water originating from the South $\mathrm{Pa}$ cific and North Pacific. This is essential for simulating a proper distribution of temperature and salt in the equatorial thermocline [Rodgers et al., 1999]. Tracer release experiments in the model revealed that twice as

Table 1. Experiments ${ }^{\mathrm{a}}$

\begin{tabular}{llc}
\hline Experiment & Model & Mask \\
\hline Control & LOAM & $\ldots$ \\
MID & LOAM & $30^{\circ} \mathrm{S}-30^{\circ} \mathrm{N}$ \\
TRP & LOAM & $<16^{\circ} \mathrm{S}$ and $>16^{\circ} \mathrm{N}$ \\
WST & LOAM2 & $\ldots$ \\
LIN & LIN & $30^{\circ} \mathrm{S}-30^{\circ} \mathrm{N}$ \\
\hline
\end{tabular}

a The first column states the name of the experiment. The second column states the model that has been used (LOAM, primitive equation ocean model coupled to atmospheric mixed layer; LOAM2, same as LOAM, but only variable forcing in the wind stress was applied; LIN, linear shallow water model forced by wind stress anomalies). The third column states the region where the anomalous forcing is applied. See text for further details. 


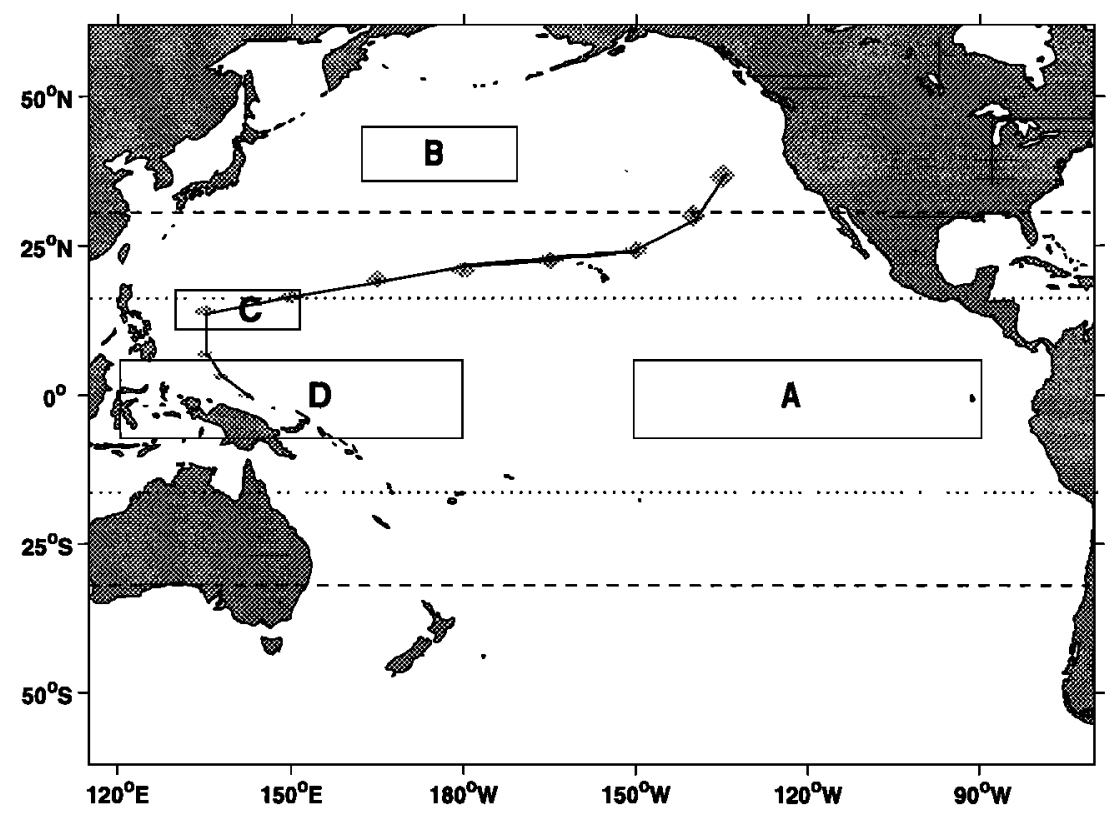

Figure 1. Schematic drawing showing the positions of the mask used in experiment MID (dashed line), TRP (dotted line) and LIN (dashed line). The continuous line shows the path along which the time-latitude diagrams in Figure 3 are made. Boxes are the areas over which the temperature and the heat content is averaged (see text).

much water is transported from the South Pacific to the equator than from the North Pacific. This is in accordance with estimates from observations [Johnson and McPhaden, 1999]. Finally, our surface heat fluxes and outgoing long-wave radiation are free to evolve. This means that the simulated SST is not overly constrained, which would be the case if air temperature and humidity were specified.

\section{Simulated Thermocline Variability}

The wind speed from the COADS data has an upward trend in the North Pacific that does not seem realistic [see Miller et al., 1994]. The trend caused an unrealistic, almost linear downward trend in the SST in the North Pacific. Therefore we removed the linear trend from the model results. The trend is possibly caused by the switch from Beaufort estimates to anemometer measurements on ships [e.g., Cardone et al., 1990]. By removing the linear trend, we might get unrealistic results in the late 1980 s and 1990 s as the switch was largely completed by the early 1980 s.

In Figure 2a we show the observed and modeled SST anomaly in the NINO3 region (region A in Figure 1). Figure $2 \mathrm{Big} \mathrm{El}$ Niño events such as those during 1972/1973 and 1983/1984 are well simulated. In Figures $2 \mathrm{~b}$ and $2 \mathrm{c}$ we show the observed and simulated upper ocean thermal anomalies (averaged temperature anomaly over the upper $440 \mathrm{~m}$ ) in the off-equatorial tropics and in the midlatitudes (regions $\mathrm{B}$ and $\mathrm{C}$ in Figure 1). Here we focus on the decadal timescales by low-pass filtering the data. In the off-equatorial tropics, the peak values around 1976 are well simulated (Figure $2 b$ ). These peaks correspond to the event discussed in section 2. The peak at 1985 is too large in the model. Also in the beginning of the run the model results differ from the observations. This discrepancy may be due to the sparsity of the observations before 1970 [Tourre et al., 1999] and to the detrending of the data. Most decadal swings are well simulated. This is true for the variations in the midlatitudes as well (Figure 2c). Here as well, most discrepancies are found at the beginning of the simulation and at the very end. In general, the model captures the tropical interannual variability and extratropical decadal variations that are observed in nature. This makes the model suitable for studying the effect of decadal extratropical variability on the tropical thermocline.

\subsection{Equatorial Upper Ocean Variability}

In Figure 3 we show the low-frequency upper ocean temperature anomalies along the equator. Figure 3 In the control experiment the signature of ENSO-like decadal variability is clear (Figure 3a). The variability consists of decadal swings in the tilt of the thermocline. For instance, from 1950 to 1960 , the eastern equatorial Pacific was anomalously warm, while the western equatorial Pacific was cold. In the early 1970s we find the opposite pattern. The standard deviation of these lowfrequency upper ocean temperature anomalies in the warm pool of the equatorial Pacific is $0.16 \mathrm{~K}$ (region D in Figure 1; Table 2). Table 2 The simulated amplitude of the low-frequency variability in the warm pool is 

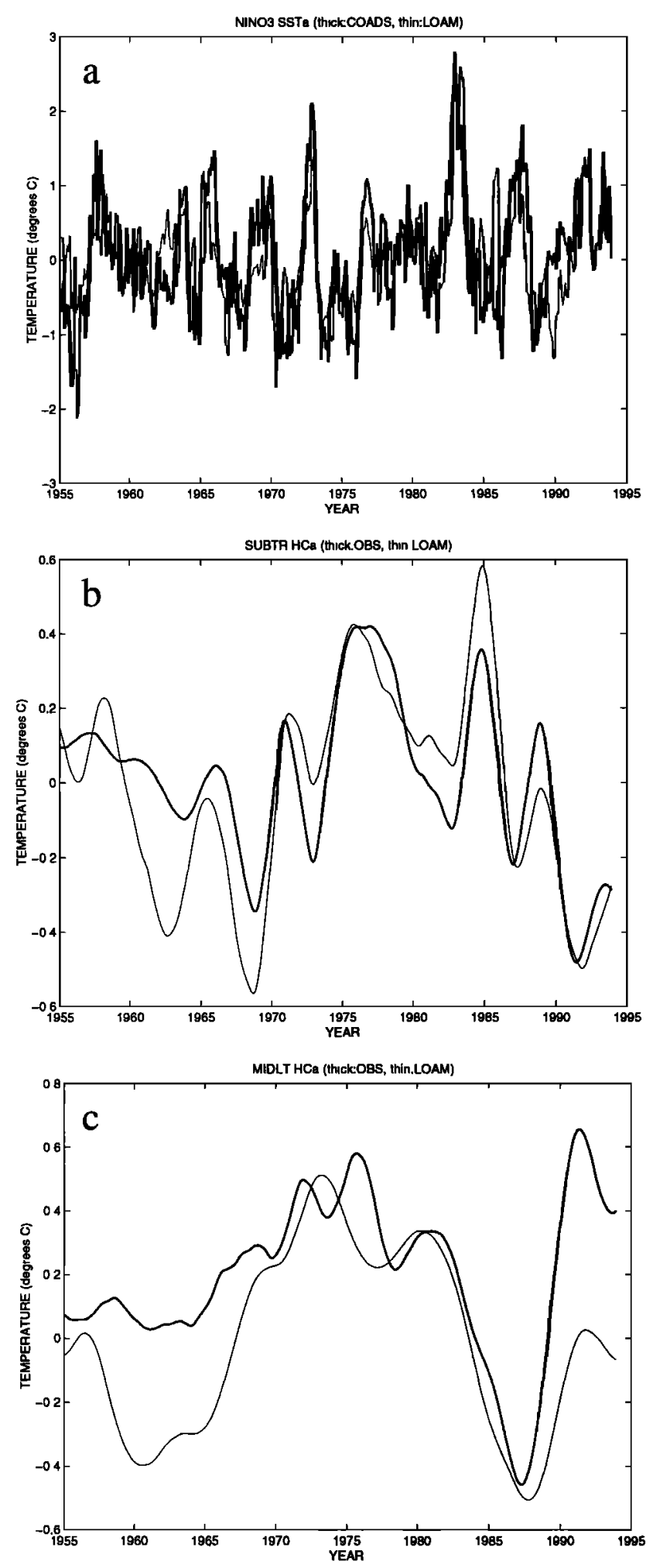

Figure 2. Observed (COADS, thick line) and modeled (control experiment, thin line) time series of (a) SST anomalies in the NINO3 region $\left(150^{\circ} \mathrm{W}-90^{\circ} \mathrm{W} ; 5^{\circ} \mathrm{N}\right.$ $5^{\circ} \mathrm{S}$, region $\mathrm{A}$ in Figure 1), (b) low-pass-filtered (4-year running mean with Parzen window) upper ocean temperature anomalies in the off-equatorial tropics $\left(130^{\circ} \mathrm{E}\right.$ $150^{\circ} \mathrm{E} ; 18^{\circ} \mathrm{N}-11^{\circ} \mathrm{N}$, region $\mathrm{C}$ in Figure 1 ), and (c) lowpass-filtered (4-year running mean with Parzen window) upper ocean temperature anomalies in the midlatitudes $\left(160^{\circ} \mathrm{E}-170^{\circ} \mathrm{W} ; 4^{\circ} \mathrm{N}-35^{\circ} \mathrm{N}\right.$, region $\mathrm{B}$ in Figure 1$)$. in excellent agreement with observations. When no filtering is applied, the modeled variability is larger than the observed variability. This is probably due to the underrated variability in the first 15 years in the observations owing to the sparsity of the data. When only data after 1970 are used, a higher value is found in the observations (Table 2).

Experiment MID was designed to investigate whether low-frequency tropical variability can be of extratropical oceanic origin. Because the surface forcing in the tropics does not vary (except for a constant seasonal cycle), any low-frequency variability in the tropics must be of extratropical origin and transfered to the tropics by the ocean. In experiment MID low-frequency equatorial thermocline variability is clearly simulated (Figure $3 \mathrm{~b}$ ). Unlike the decadal variations in the observations, the decadal swings consist of deepening and shallowing of the thermocline rather than changes in the tilt of the thermocline. This is indicated by the single-signed upper ocean temperature anomalies along the equator. This distinct response of the equatorial thermocline to extratropical variability will be discussed further in section 5.

Although an impact of the midlatitudes on the equatorial thermocline is found, the amplitude is very small. Only a sixth of the observed decadal equatorial variability is simulated; that is, the standard deviation of upper ocean temperature in the warm pool is only 0.03 $\mathrm{K}$ (Table 2). Interestingly, this variability occurs almost entirely at low frequencies. The variations along the equator in experiment MID are quite unlikely related to the observed variations and the variations in the control run.

A small impact of the midlatitudes on the equatorial region was also found by Lysne et al. [1997] and Schneider et al. [1999b]. Whether the coupled ENSO phenomenon is affected by the small low-frequency variations could not be simulated with the present model.

\subsection{Origin of the Thermal Anomalies in the Tropics}

In the previous section we showed that the impact of midlatitude oceanic anomalies on the equatorial thermocline is small, but not negligible. As this may still be important, we focus on the origin of the anomalies in this section. Here we study whether propagation of anomalies from the midlatitudes to the western boundary in the tropics induces this equatorial low-frequency variability. As was shown in section 2 this is not evident from observed upper ocean temperature anomalies.

Figure 4a shows the upper ocean temperature anomalies in experiment "control" along the path that is depicted in Figure 1 (from now on, upper ocean temperature, or heat content, is defined as the vertically averaged temperature between 0 and $440 \mathrm{~m}$ ). Figure 4 This pathway mimics the advective pathway along which thermal anomalies propagate from the midlati- 

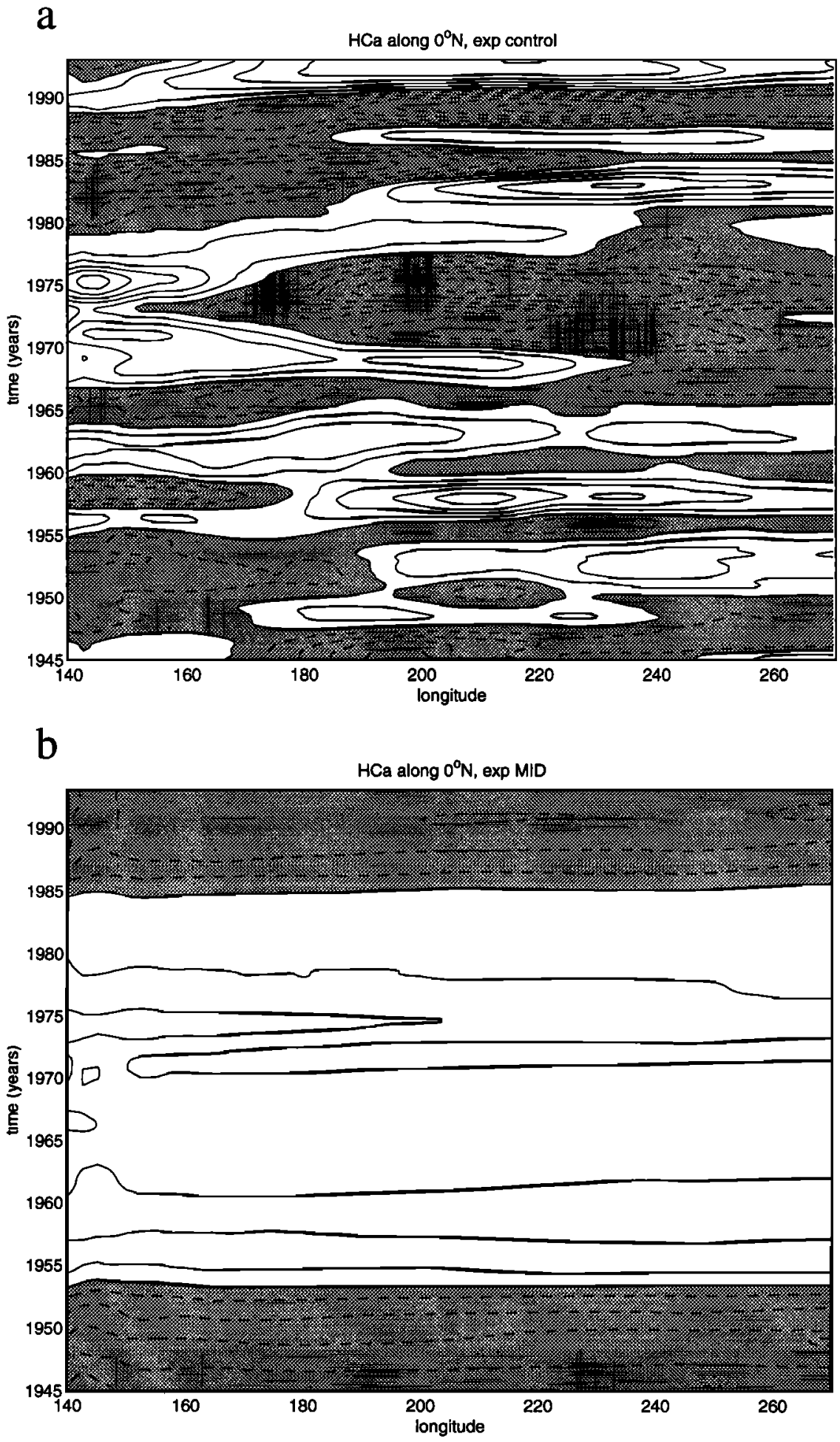

Figure 3. Low-pass-filtered (4-year running mean with Parzen window) upper ocean temperature anomalies along the equator in (a) experiment control (contour interval, $0.1 \mathrm{~K}$ ) and (b) experiment MID (contour interval, $0.02 \mathrm{~K}$; negative values are shaded).

tudes to the tropics. The pathway was constructed by using the apparent propagation in the observations and results from tracer release experiments in the model. No clear propagation takes place in experiment control. Furthermore, the equatorial low-frequency variability is uncorrelated with the off-equatorial variability.
In experiment MID anomalies of upper ocean temperature are found well south of $30^{\circ} \mathrm{N}$ where no anomalous surface forcing is applied (Figure 4b). These anomalies must be generated by oceanic heat transport. However, the amplitude of the anomalies is small (note the different contour interval compared with Figure 4a). Prop- 
Table 2. Standard Deviation of Upper Ocean Temperature (Kelvins) in the Warm Pool of the Tropical Pacific $\left(5^{\circ} \mathrm{S}-5^{\circ} \mathrm{N}, 120^{\circ} \mathrm{E}-180^{\circ} \mathrm{E}\right.$, Region D of Figure 1$)$.

\begin{tabular}{lcc}
\hline Data & Low-Pass-Filtered $(>4$ Years $)$ & No Filter \\
\hline Observed & 0.16 & $0.31(0.37$ after 1970) \\
Control & 0.16 & 0.35 \\
MID & 0.03 & 0.03 \\
TRP & 0.17 & 0.36 \\
LIN & 0.02 & 0.02 \\
\hline
\end{tabular}

agation is clearest between $25^{\circ} \mathrm{N}$ and $15^{\circ} \mathrm{N}$. South of $15^{\circ} \mathrm{N}$, no propagation is found. This implies that the anomalies stay north of the North Equatorial Current, where the upward doming isopycnals act as a potential vorticity barrier for the anomalies.

Propagation into the equatorial region of thermal anomalies from the South Pacific seems more likely because the transport in the upper ocean from the subtropics to the tropics is larger from the South Pacific than from the North Pacific. The observations are too sparse to deduce whether propagation of anomalies takes place. Tracer release experiments in the model showed that more upper ocean water is transfered from the South Pacific to the equator than from the North Pacific. Also an interior path was present in correspondence with, for example, R.X. Huang (Interior communication and the structure of the thermocline in subtropical and tropical oceans, submitted to Journal of Physical Oceanography), but transport along the western boundary still dominated. However, we do not find propagation of thermal anomalies from the South $\mathrm{Pa}$ cific (not shown). Note that the region where subduction takes place of water ventilating the equatorial thermocline from the South Pacific may be equatorward of $30^{\circ} \mathrm{S}$, that is, in the region where there is no anomalous forcing in experiment MID.

This experiment shows that thermal anomalies generated in the midlatitudes do not connect with the equatorial Pacific by an advective path along the subtropical gyre. However, the sign of the anomalies at the equator is almost identical to that in the western off-equatorial tropics. The absence of a lag of several years between the anomalies at $15^{\circ} \mathrm{N}$ and the anomalies at the equator suggests that anomalies propagate fast from the western tropics into the equatorial region along the western boundary. We will come back to this potential mechanism of subtropics-tropics interaction in section 5 .

Along $15^{\circ} \mathrm{N}$ and $20^{\circ} \mathrm{N}$, two and a half cycles of an interdecadal cycle is present (Figure 4b). This regular cycle seems to correspond to the cycle found by Tourre et al. [1999]. They used observations of upper ocean temperature after 1970 and show only one cycle. Our model results suggest that indeed, a regular interdecadal cycle is present in the upper ocean from 1945 on. Furthermore, this experiment shows that oceanic heat transport is responsible for generating this interdecadal mode of variability in the off-equatorial tropics.
The anomalies in the tropics in experiment MID are small in comparison with the anomalies in experiment control (Figures 4a and 4b). Since advection is not a dominant mechanism for generating these thermal anomalies, the question arises as to what alternative mechanism generates the anomalies in this region. Atmospheric forcing is the main candidate. Atmospheric forcing creates heat anomalies in the ocean either by the surface heat fluxes or by Ekman divergence and convergence due to varying wind stresses. Also, changes in turbulent mixing in the mixed layer due to varying surface fluxes can create anomalies.

A run with only varying wind stress (experiment WST) was performed to distinguish the effect of the wind-driven variability from the variability induced by surface forcing. In LOAM the surface heat fluxes are determined by a bulk transfer relation. By keeping the wind speeds and the winds that advect air temperature and humidity to their climatological value, we largely remove the heat flux forcing. However, changes in the Ekman transport divergence can introduce significant upper ocean heat content anomalies. In Figure 4c we show the upper ocean temperature anomalies along the advective path for this experiment. When compared with Figure 4a, it is evident that most tropical variability is captured in this experiment. Since advection from midlatitudes is small, this implies that most variability is induced by local anomalous divergence/convergence in the upper ocean due to the varying wind stress or by propagating Rossby waves from tropical origin. The difference between the control experiment and experiment WST shows the effect of the surface heat fluxes. Indeed, the surface heat fluxes make a very small contribution and act to damp the anomalies (Figure 4d).

To confirm that anomalies in the tropics are almost entirely generated by local tropical processes we performed experiment TRP. Only very small differences could be found between experiment TRP and the control experiment (not shown).

\subsection{Example of a Locally Forced Thermal Anomaly}

In section 2 we showed an apparent advective path of thermal anomalies from the midlatitudes toward the tropics along the southern rim of the subtropical gyre. However, the connection between the anomalies in the central subtropical Pacific and the western tropical Pa- 

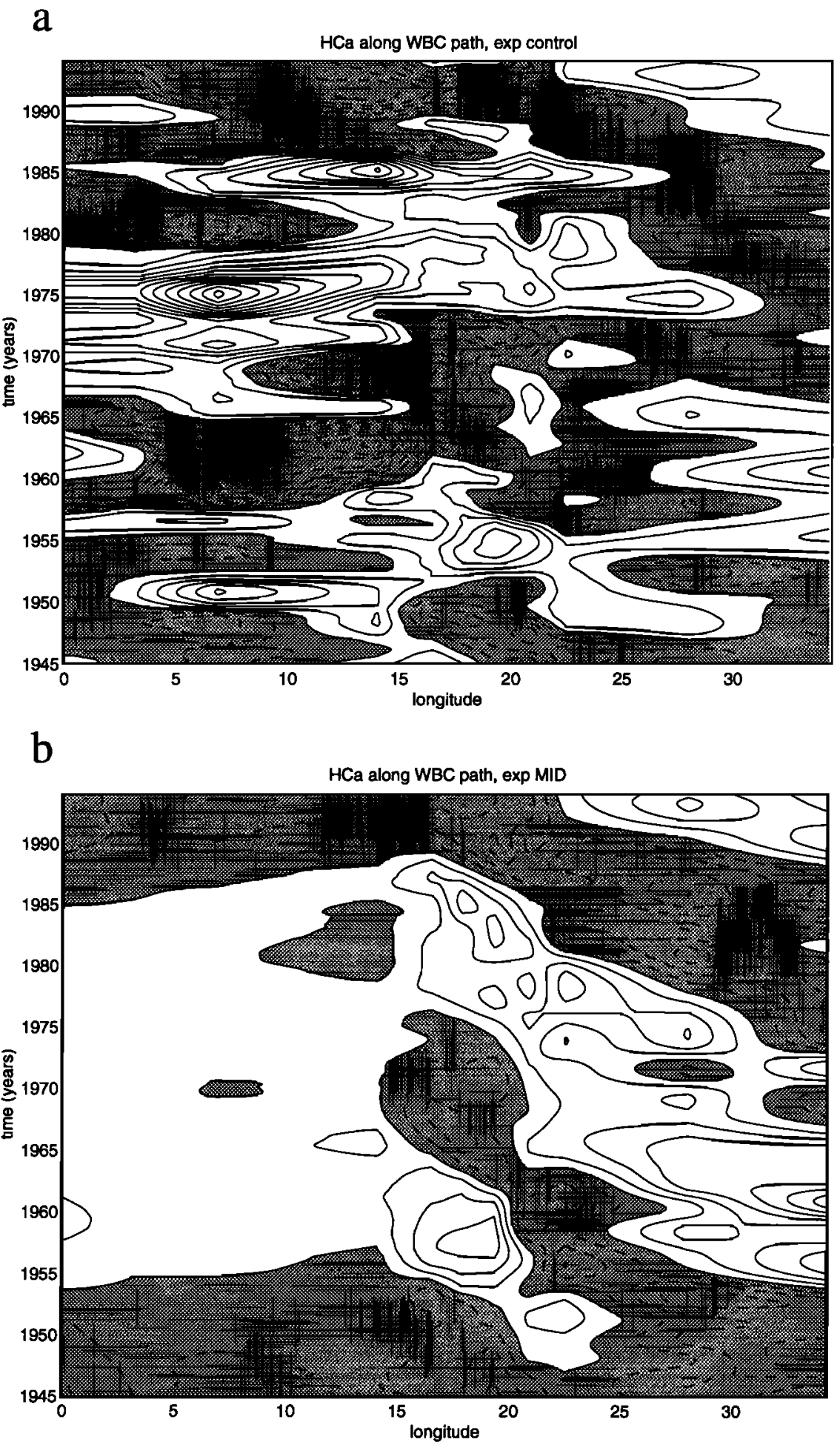

Figure 4. Low-pass-filtered (4-year running mean with Parzen window) upper ocean temperature anomalies along the ventilation pathway depicted in Figure 1. (a) Experiment control (contour interval, $0.1 \mathrm{~K}$ ); (b) experiment MID (contour interval, $0.05 \mathrm{~K}$ ); (c) experiment WST (contour interval, $0.1 \mathrm{~K}$; negative values are shaded); and (d) experiment control minus WST (contour interval, $0.05 \mathrm{~K}$; negative values are shaded).

cific was not clear. The key question is whether the anomalies in the western off-equatorial tropics of the North Pacific are formed by advection of heat anomalies or by another mechanism. Therefore we examine the mechanisms that generate upper ocean temperature variability in the western tropics in more detail.

In Figure 5 we show time series of upper ocean temperature anomalies in the western tropics derived from 

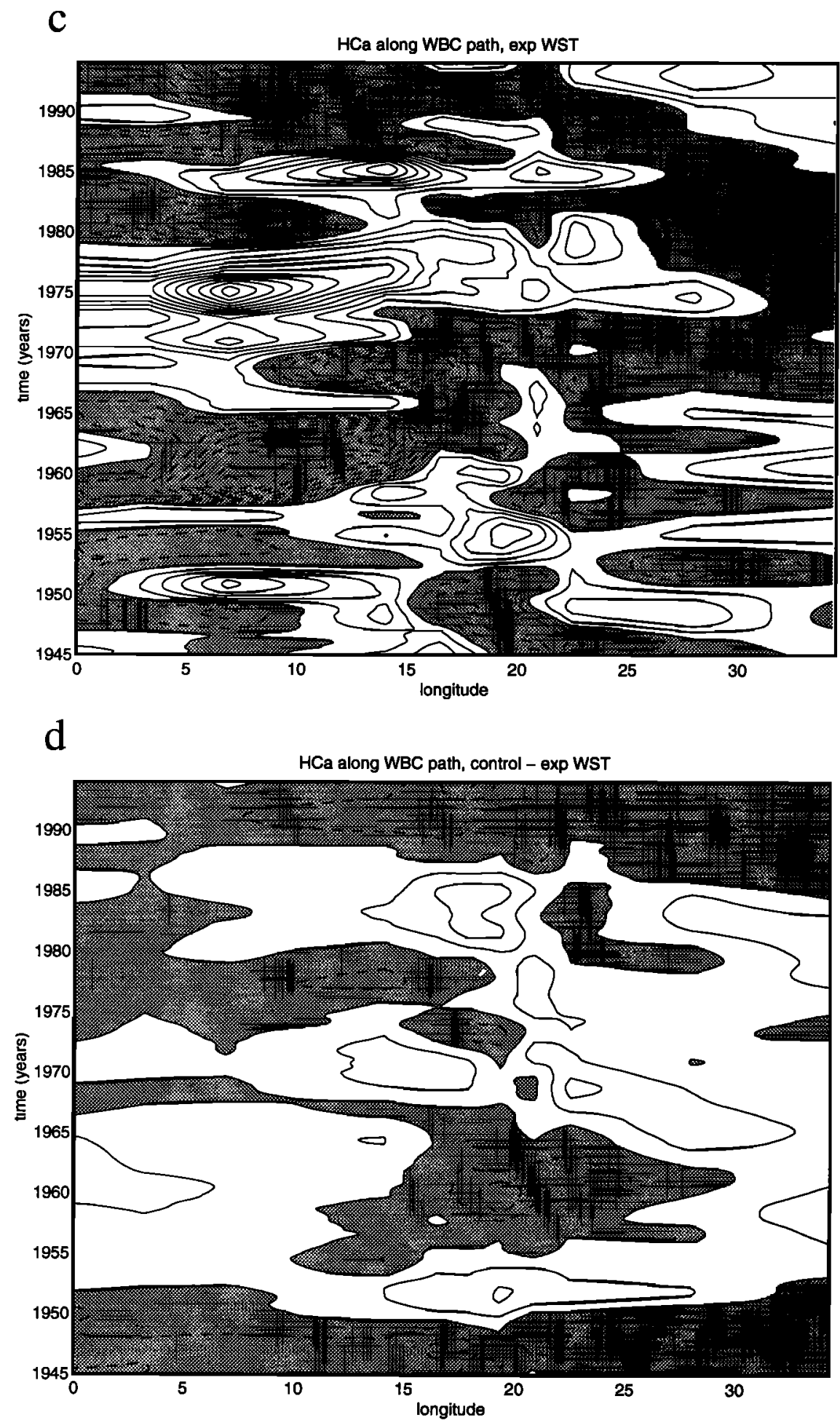

Figure 4. (continued)

the different model experiments (see also Figure 2c where observed anomalies from the same area (region $\mathrm{C}$ in Figure 1) are shown). Figure 5 The observed time series is dominated by a number of peaks. The largest has its maximum around 1978. Plate 1 shows the spatial distribution of the anomalies at that time. It is evident that the very same peak is simulated in the model with tropical forcing only (experiment TRP, Figure 5). Also the peaks in 1985 and 1990 are well simulated in this experiment. Since the forcing north of $16^{\circ} \mathrm{N}$ is constant in this experiment, the anomalies must be locally generated. We conclude that this anomaly cannot be from extratropical oceanic origin such as was suggested by, for example, Zhang et al. [1998]. This is also confirmed by experiment MID which shows hardly low-frequency variability in the western tropics (Figure 5). This example confirms the suggestion made in sections 2 and 4.2 . On the basis of the observations and the model exper- 


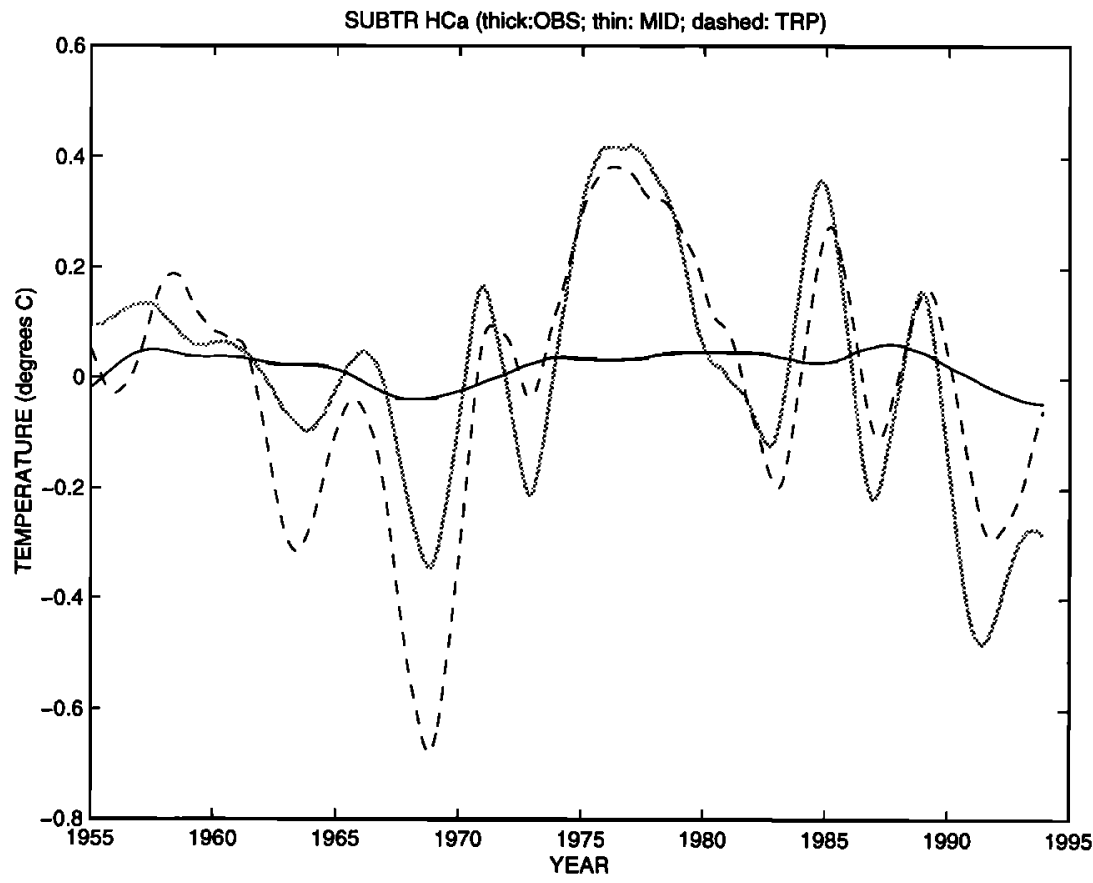

Figure 5. Low-pass-filtered (4-year running mean with Parzen window) upper ocean temperature anomalies in the off-equatorial tropics $\left(130^{\circ} \mathrm{E}-150^{\circ} \mathrm{E} ; 18^{\circ} \mathrm{N}-11^{\circ} \mathrm{N}\right.$, region $\mathrm{C}$ in Figure 1 ; see also Figure 2c) in the observations (thick line), experiment MID (thin line), and TRP (dashed line).

iments, the thermal anomalies in the western tropical North Pacific are locally generated. However, the tropical wind variations that generate the anomalies could be of nonlocal origin. Also, in experiment WST the observed anomalies are well simulated (not shown, but already evident from Figure 4c). This indicates that local Ekman divergence and convergence are responsible for creating the anomalies. Although advection may have preceded the strong anomaly and an unstable air/sea feedback could have enhanced the anomalies, the above results show that is not a very likely mechanism.

\section{Discussion}

In the previous sections we have shown that the impact of variability in the midlatitudes on the tropical thermocline by oceanic heat transport is small but not entirely negligible. Experiment MID has shown that advection by the mean flow was not responsible for the small response in the equatorial region. The absence of a time lag between variability in the western off-equatorial tropics and the equatorial region suggests another mechanism. Anomalies could be generated in the midlatitudes and propagate as coastal Kelvin waves anticlockwise to the equator such as envisaged by, for example, Lysne et al. [1997] and Liu et al. [1999]. If this mechanism generates low-frequency variability in the equatorial thermocline, the response found in experiment MID should be consistent with linear theory. Therefore to test the aforementioned hypothesis we forced a linear shallow water model (see section 3.1 ) with observed wind stress anomalies north of $30^{\circ} \mathrm{N}$ and south of $30^{\circ} \mathrm{S}$ (experiment LIN), equivalent to experiment MID.

The linear model calculates thermocline depth disturbances with respect to a mean thermocline depth of $175 \mathrm{~m}$. The depth anomalies can be translated into upper ocean temperature anomalies by using the mean vertical temperature distribution. The standard deviation of the upper ocean thermal anomalies in the tropical warm pool in the linear model is $0.02 \mathrm{~K}$ (Table 2). This is close to the variability in experiment MID taking into account the idealizations in the linear model. Most variability takes place at low frequencies, which is in accordance with experiment MID.

In Figure 6a we show the thermal anomalies along the equator of experiment LIN. Figure 6 Just as in experiment MID, there are slow decadal variations along the equator. Also, there is no zonal variation; that is, the anomalies correspond to changes in the mean depth of the thermocline. Qualitatively, this result is consistent with the result found in experiment MID by using the LOAM model (see Figure 4b).

So the amplitude and the spatial structure compare favorably, but there are large differences between results of both experiments in the time domain as shown in Figure 7. Figure 7 Here the upper ocean temperatures in the eastern and western equatorial Pacific for the different experiments are plotted. The time series in the east and in the west are in phase in experiment LIN and experiment MID, but the times of occurrence of maxima and minima do not correspond. In exper- 

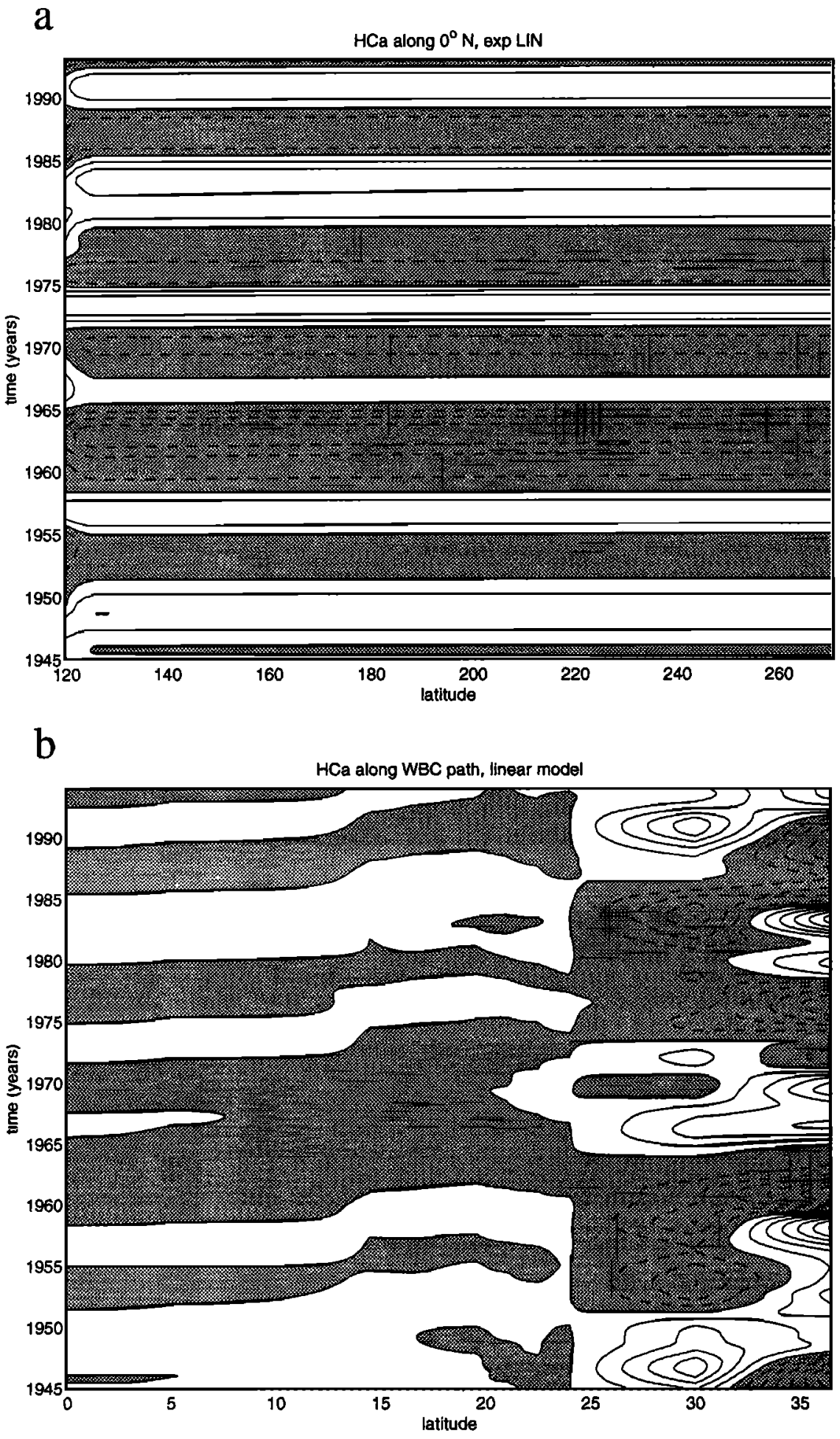

Figure 6. Low-pass-filtered (4-year running mean with Parzen window) upper ocean temperature anomalies (Kelvins) in experiment LIN. (a) Along the equator (contour interval, $0.01 \mathrm{~K}$; negative values are shaded) and (b) along the ventilation pathway (contour interval, $0.1 \mathrm{~K}$; negative values are shaded).

iment control the decadal variation in the tilt of the thermocline associated with the decadal ENSO signal is visible as indicated by the out-of-phase behavior.

Differences between the results of the linear model and the LOAM model may have been caused by, for instance, the assumption of a uniform vertical density gradient over the entire Pacific in the linear model and the associated lack of mean flow. Anomalies generated by wind stress anomalies in the North Pacific propagate westward as Rossby waves. Upon arrival at the boundary they propagate fast into the tropics as Kelvin waves. This can be seen in Figure 8 where standard deviations 

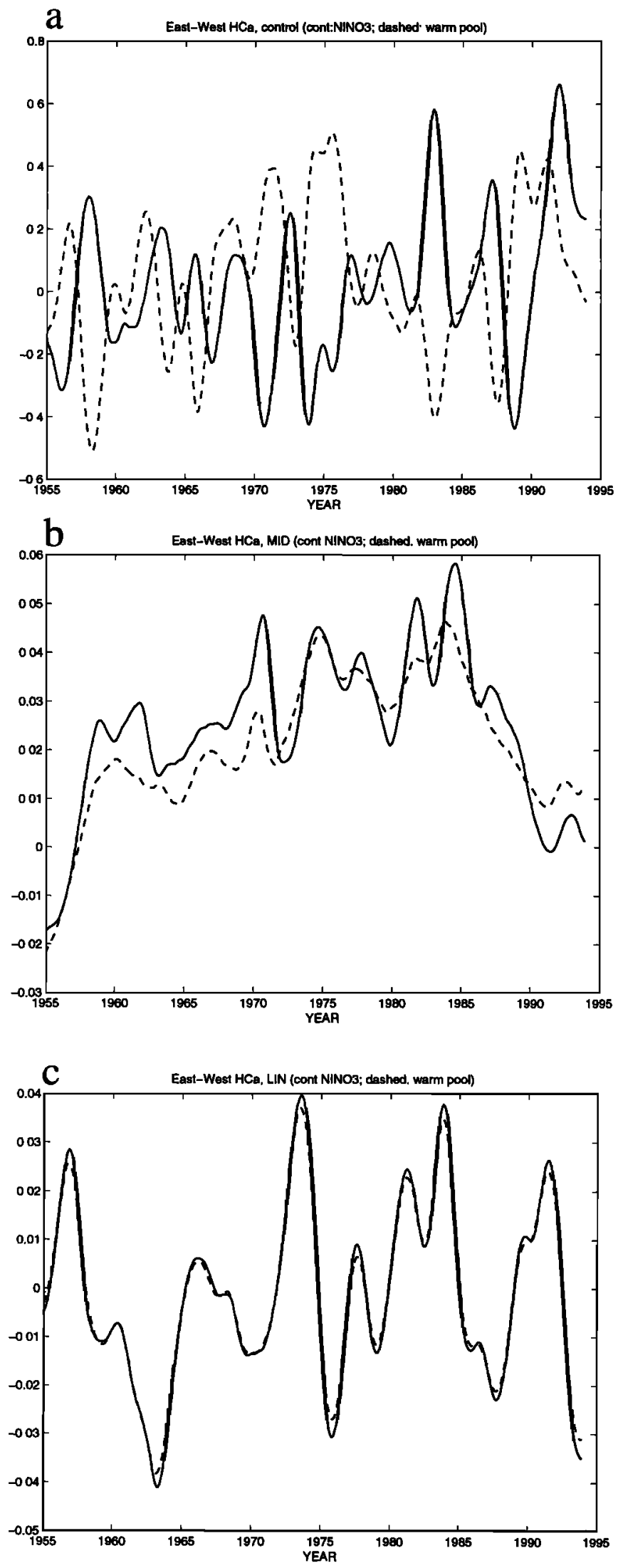

Figure 7. Time series of low-pass-filtered (2-year running mean with Parzen window) upper ocean temperature anomalies (Kelvins) in (a) experiment control, (b) experiment MID, and (c) experiment LIN. of the upper ocean temperature anomalies are shown for both experiments. Large anomalies are found north of $30^{\circ} \mathrm{N}$ in experiment LIN, but south of $30^{\circ} \mathrm{N}$ anomalies are only found along the western boundary (tapering of the forcing towards zero causes anomalies to be found south of $30^{\circ} \mathrm{N}$ ). Figure 8 The anomalies along the western boundary are the signature of the Kelvin waves. In the LOAM model, anomalies propagate along a path along the subtropical gyre well south of $30^{\circ} \mathrm{N}$ before arriving at the western boundary. Then they propagate fast into the equatorial Pacific as well, although this propagation is less clear than that in the linear model. The lack of propagation along this path due to the absence of a mean flow in the linear model is also clear in Figure $6 \mathrm{~b}$ and can explain differences in the time domain.

A common feature of the experiment MID and experiment LIN is the zonally uniform response along the equator. The zonally uniform response occurs only at low frequencies. At higher frequencies, variations in the tilt of the thermocline are found. This can be seen in Figure 9 where spectra are presented of the difference between the phase angle of time series of upper ocean temperature in the NINO3 region and in the warm pool region (see Figure 1, regions A and D). Figure 9 The phase angle of the complex transfer function $G(\omega)=f_{e w}(\omega) / f_{e}(\omega)$ is plotted, with $\omega$ the frequency, $f_{e w}(\omega)$ the cross spectral density, and $f_{e}(\omega)$ the power spectral density of the individual time series. Subscript $e$ stands for the time series in the east (NINO3), and subscript $w$ for the time series in the west (warm pool).

A value near $\pi$ means that the time series in the eastern and western Pacific are out of phase. When the value is zero, the time series are in phase. For experiment control, out of phase relationships are found at nearly all frequencies. This reflects the ENSO mode at high as well as at low frequencies. This is in accordance with observations that show interannual ENSO signals and ENSO-like (inter)decadal signals in the equatorial Pacific [Zhang et al., 1997]. The mode is associated with variability in the wind stress in the equatorial Pacific. The phase angle differences in experiment MID and LIN show a different behavior. At high frequencies the time series are out of phase. The phase angle drops to zero after a few years. For experiment LIN this is most clear. At a period of 6 years the angle has become zero, which corresponds to a zonally uniform response. For experiment MID the picture is somewhat less clear, but the phase angle clearly drops for decreasing frequencies. At a period of about 8 years the angle becomes zero. Although there are quantitative differences between the results of the LOAM model and the linear model for reasons that have been stated above, the similarities in the frequency domain (Figures $9 \mathrm{~b}$ and 9c) lead to the conclusion that the same physical mechanisms of equatorial thermocline variability are acting in both models. That is, at high frequencies free equatorial 

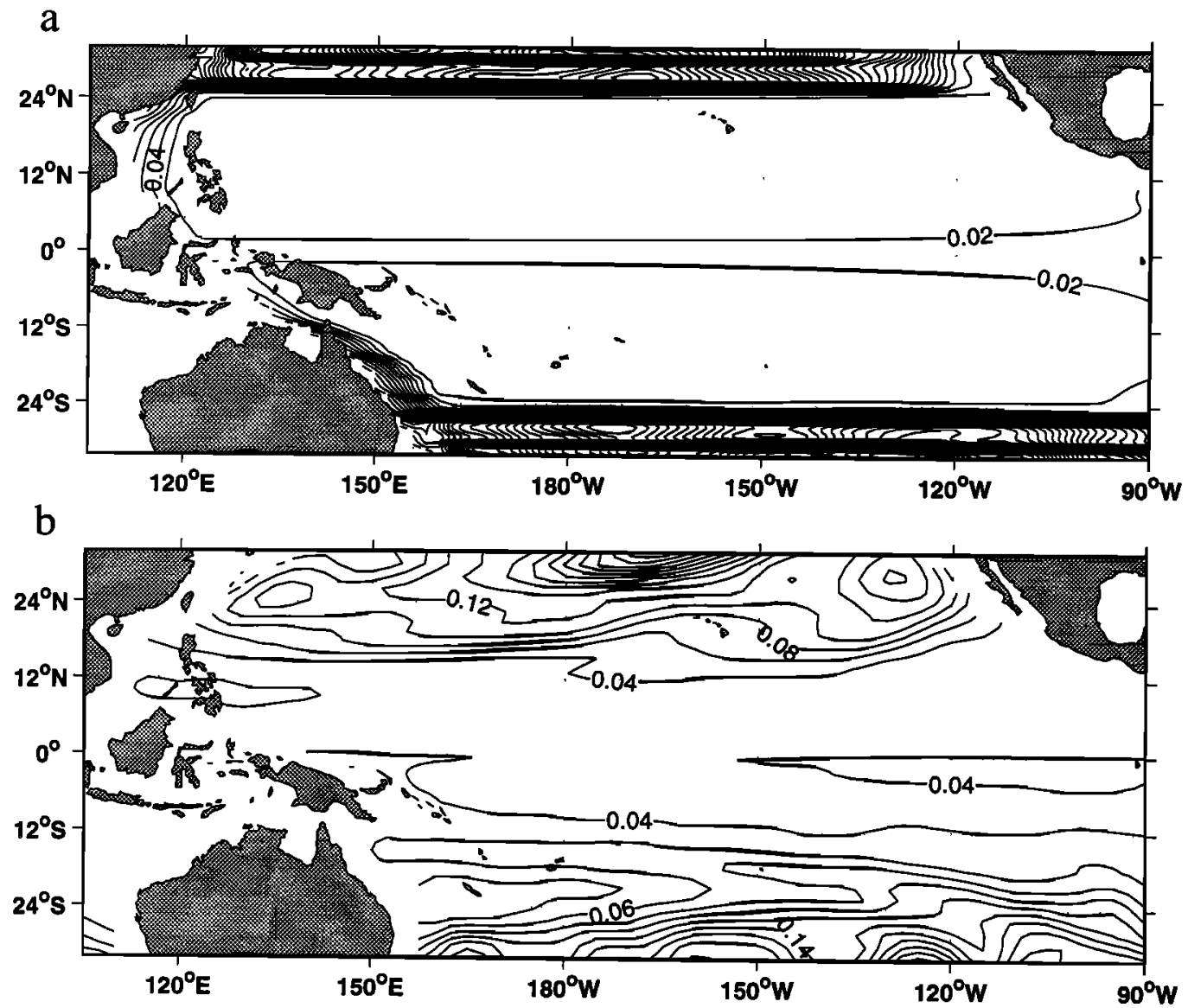

Figure 8. Standard deviation of upper ocean temperature (Kelvins) in (a) experiment LIN and (b) experiment MID.

modes are found as reflected by out-of-phase relationships between the eastern and western Pacific. These are equatorial Kelvin and Rossby waves that build up to an equatorial basin mode at low frequencies [Cane and Moore, 1981]. The basin mode consists of a zonally uniform deepening and shallowing of the thermocline (see also Figures $3 \mathrm{~b}$ and $6 \mathrm{a}$ ). It is worth noting that the analytical solution of Cane and Moore [1981] (their equation (12)) also has a break from zero phase at these low frequencies.

In experiment control there are free and forced modes of equatorial variability at high and low frequencies. The large-amplitude differences between the upper ocean temperature variations in experiment control and experiment MID imply that the forced response dominates over the effect of the free basin modes. Unlike the low-frequency basin modes, the response to wind stress anomalies consists of a change in the tilt of the thermocline. This is in accordance with the findings in the previous sections.

\section{Conclusions}

Observations of heat content suggest propagation of thermal anomalies along the westward return flow of the subtropical gyre. Previnus studies have suggested that these anomalies connect with the tropical thermocline and affect the equatorial thermocline [ $G u$ and Philander, 1997]. The propagating anomalies would be part of a cycle of a decadal extratropical-tropical climate oscillation. In the current data record, two events are present when propagation in the off-equatorial tropics takes place, but we have shown that the connection to the equatorial region is not convincingly clear. Anomalies formed by subduction in the eastern North Pacific seem to fade away in the subtropical and tropical Pacific rather than propagating into the equatorial region.

Model experiments have been performed to investigate the apparent connection between the extratropical Pacific and the tropical Pacific. We found that anomalies propagate from the midlatitudes into the tropics. Advection of anomalies takes place from the east toward the west, following the westward return flow of the subtropical gyre. Interdecadal variability induced by midlatitude variability could be observed in the offequatorial tropics. The amplitude, however, is small. The anomalies hardly propagate into the equatorial region from either hemisphere. Based on the model experiments, a sixth of the variability in the equatorial thermocline can be attributed to oceanic variability in 

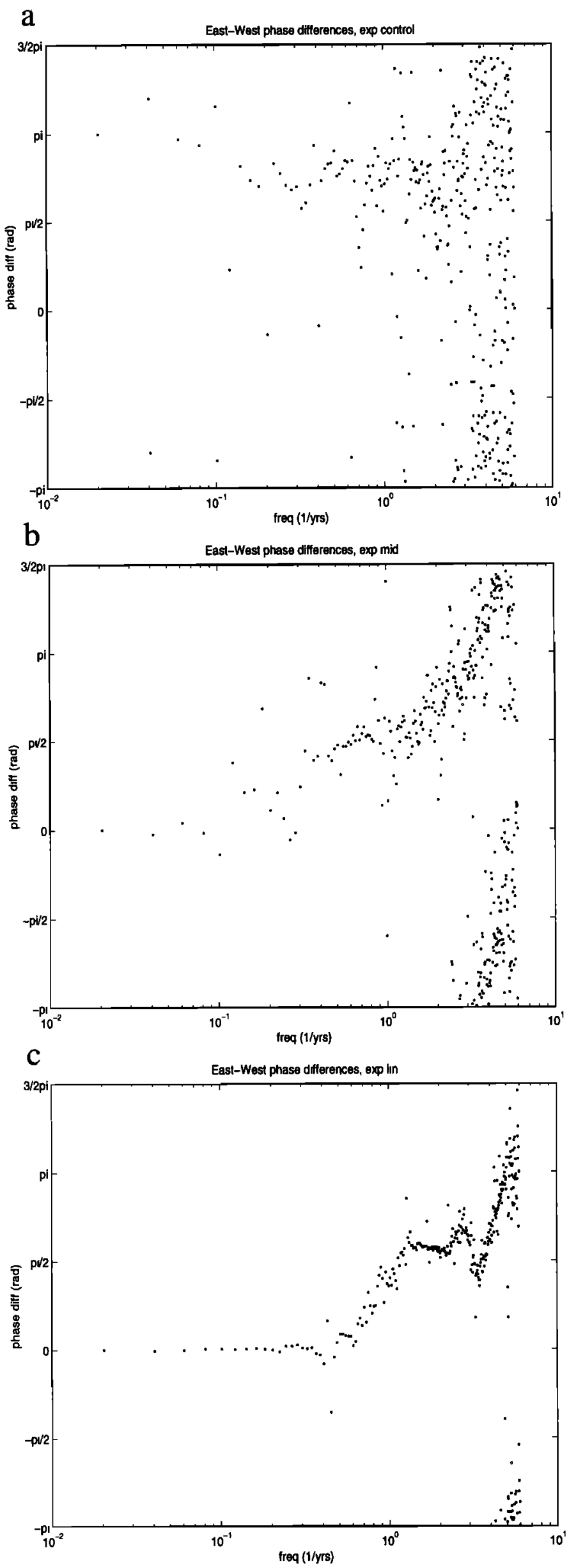

the midlatitudes The remaining low-frequency variability in the tropics is mainly of local origin, forced by wind stress variations. The origin of decadally varying tropical wind stress variations could not be studied in the present setup. The variations could be locally generated but can also be related to, for instance, the Asian monsoon [Masumoto and Yamagata, 1991] or midlatitude decadal variability [Barnett et al., 1999].

Results from an experiment with a linear shallow water model showed similar features as the experiments with the primitive equation model. The most distinct feature is that the response to extratropical wind stress variability consists of a change in the mean depth of the equatorial thermocline. This is in contrast to the response to local tropical wind stress anomalies. In that case the tilt of the thermocline would be affected. At high frequencies, however, when no anomalies in the forcing were applied, changes in the tilt were found. These correspond to the free equatorial basin modes. These modes build up to a basin mode at low frequencies. The low-frequency mode consists of a zonally uniform deepening and shallowing of the thermocline. The linear model showed that extratropical oceanic thermocline disturbances can reach the tropics by propagation along the western boundary as coastal Kelvin waves. This explains the small time lag between variability in the western off-equatorial tropics and the equatorial region.

The emphasis of this study has been on the propagation of thermal anomalies by the mean flow and its impact on tropical upper ocean temperature. Another scenario by which the tropical SST could be affected is by variations in the strength of the Subtropical Cell [Kleeman et al., 1999]. In the observations and in the model there is no clear evidence for this mechanism as well. However, the mask in experiment MID may extend too far poleward as the downwelling branches of the Subtropical Cells are located around $20^{\circ} \mathrm{N}$ and $20^{\circ} \mathrm{S}$. Also, the relatively coarse resolution of the model prohibits generation of eddy-induced internal ocean variability that may have affected the results.

Our results confirm findings from previous studies. Schneider et al. [1999b] used an ocean-only model to show that the impact of oceanic advection of thermal anomalies from the midlatitudes to the equator is small. In a coupled ocean-atmosphere model, Pierce et $e l$. [2000] could not find evidence for an advective path as well. Using a different model with a different configuration, we come to the conclusion that the impact of the midlatitudes on the tropics by oceanic processes is small. The analysis of observed upper ocean heat con-

Figure 9. Spectrum of phase angle differences between time series of upper ocean temperature in the eastern tropical Pacific (region A in Figure 1) and the western tropical Pacific (region D in Figure 1). (a) Experiment control, (b) experiment MID and (c) experiment LIN. 
tent confirms our findings. In addition, we have shown that the observed low-frequency tropical variability is almost entirely forced by local wind stress variations. This confirms the results of the coupled model study by Pierce et al. [2000]. Finally, we have shown that the response of the equatorial thermocline to midlatitudinal oceanic variations is consistent with linear wave dynamics, but it is modified by the mean flow.

Although the impact of extratropical wind variations on the equatorial thermocline is small, it is not entirely negligible. We plan to study how the changes in the mean depth of the thermocline affects ENSO in a coupled ocean-atmosphere model in the future.

Acknowledgments. W.H. likes to thank the people of the Oceanography and Climate group at Lamont-Doherty for the hospitality during his stay. Richard Seager and Yochanan Kushnir are thanked for stimulating discussions. M.A.C., A.K., and N.N. are supported by grant OCE9819538 from the National Science Foundation.

\section{References}

Barnett, T. P., D. W. Pierce, M. Latif, D. Dommenget, and R. Saravanan, Interdecadal interactions between tropics and midlatitudes in the Pacific basin, Geophys. Res. Lett., 26, 615-618, 1999.

Bishop, J. K. B., and W. B. Rossow, Spatial and temporal variability of global surface solar irradiance, J. Geophys. Res., 96, 16839-16858, 1991.

Cane, M. A., and D. W. Moore, A note on low-frequency equatorial basin modes, J. Phys. Oceanogr., 11, 1578$1584,1981$.

Cane, M. A., and E. S. Sarachik, Forced baroclinic ocean motion II: The equatorial unbounded case, J. Mar. Res. 35, 395-432, 1977.

Cane, M. A., and E. S. Sarachik, The response of a linear baroclinic equatorial ocean to periodic forcing, $J$. Mar. Res., 39, 651-693, 1981.

Cane, M. A., S. E. Zebiak, and Y. Xue, Model studies of long-term behavior of ENSO in natural climate variability on decade-to-century time scales, in DEC-CEN Workshop, edited by D. G. Martins, K. Bryan, M. Ghil, M. M. Hall, T. R. Karl, E. S. Sarachik, S. Sorooshian, and L. D. Talley, pp. 442-457, National Academy Press, Washington, D. C., 1995

Cardone, V. J., J. F. Greenwood, and M. A. Cane, On trends in marine surface wind observations, J. Clim., 3, 113-127, 1990.

Da Silva, A. M., C. C. Young, and S. Levitus, Atlas of Surface Marine Data 1994, vol. 1, Algorithms and Procedures, NOAA Atlas 6, 83 pp., Natl. Oceanic and Atmos. Admin., U.S. Dep. of Commer., Washington, D. C., 1994.

Deser, C., M. A. Alexander, and M. S. Timlin, Upper ocean thermal variations in the North Pacific during 1970-1991, J. Clim., 9, 1840-1855, 1996.

Fine, R. A., W. H. Peterson, and H. G. Ostlund, The penetration of tritium into the tropical Pacific, J. Phys. Oceanogr., 17, 553-564, 1987.

Gu, D., and S. G. H. Philander, Interdecadal climate fluctuations that depend on exchanges between the tropics and extratropics, Science, 275, 805-807, 1997.

Hazeleger, W., R. Seager, M. Visbeck, N. Naik, and K. Rodgers, On the impact of the midlatitude storm track on the upper Pacific Ocean, J. Phys. Oceanogr., 31, 616636, 2001.
Israeli, M., N. Naik, and M. A. Cane, An unconditionally stable scheme for the shallow water equations, Mon. Weather Rev., 128, 810-823, 2000.

Johnson, G. C., and M. J. McPhaden, Interior pycnocline flow from the subtropical to the equatorial Pacific Ocean, J. Phys. Oceanogr., 29, 3073-3089, 1999.

Kleeman, R., J. P. McCreary, and B. A. Klinger, A mechanism for generating ENSO decadal variability, Geophys. Res. Lett., 26, 1743-1746, 1999.

Levitus, S. and T. P. Boyer, World Ocean Atlas 1994, vol. 4, Temperature, NOAA Atlas 4, 117 pp., Natl. Oceanic and Atmos. Admin., U.S. Printing Office, Washington, D. C., 1994.

Levitus, S., R. Burgett, and T. P. Boyer, World Ocean Atlas 1994, vol. 4, Salinity, NOAA Atlas 3, 99 pp., Natl. Oceanic and Atmos. Admin., U.S. Printing Office, Washington, D. C., 1994.

Liu, Z., L. Wu, and E. Bayler, Rossby wave-coastal Kelvin wave interaction in the extratropics, part I, Low-frequency adjustment in a closed basin, $J$. Phys. Oceanogr., 29, 2382-2404, 1999.

Lysne, J., P. Chang, and B. Giese, Impact of extratropical Pacific on equatorial variability, Geophys. Res. Lett., 24, 2589-2592, 1997.

Mantua, N. J., S. R. Hare, Y. Zhang, J. M. Wallace, and R. C. Francis, A Pacific interdecadal climate oscillation with impacts on the salmon production, Bull. Am. Meteor. Soc., 78, 1069-1079, 1997.

Masumoto, Y., and T. Yamagata, Response of the western tropical Pacific to the Asian winter monsoon: The generation of the Mindanao Dome, J. Phys. Oceanogr., 21, 1386-1398, 1991.

Miller, A. J., D. R. Cayan, T. P. Barnett, N. E. Graham, and J. M. Oberhuber, Interdecadal variability of the Pacific Ocean: Model response to observed heat flux and wind stress anomalies, Clim. Dyn., 9, 287-302, 1994.

Neelin, J. D., D. S. Battisti, A. C. Hirst, F. F. Jin, Y. Wakata, T. Yamagata, and S. E. Zebiak, ENSO theory, J. Geophys. Res., 103, 14,261-14,290, 1998.

Pierce, D. W., T. P. Barnett, and M. Latif, Connections between the Pacific Ocean tropics and midlatitudes on decadal time scales, J. Clim., 13, 1173-1194, 2000.

Rodgers, K. B., M. A. Cane, N. H. Naik, and D. P. Schrag, The role of the Indonesian Throughflow in equatorial Pacific thermocline ventilation, J. Geophys. Res., 104 20,551-20,570, 1999.

Rothstein, L. M., R. H. Zhang, A. J. Busalacchi, and D. Chen, A numerical simulation of the mean water pathways in the subtropical and tropical Pacific, J. Phys. Oceanogr., 28, 322-343, 1998.

Schneider, N., A. J. Miller, M. A. Alexander, and C. Deser, Subduction of decadal North Pacific temperature anomalies: Observations and dynamics, J. Phys. Oceanogr., 29, 1056-1070, 1999a.

Schneider, N., S. Venzke, A. J. Miller, D. W. Pierce, T. P. Barnett, C. Deser, and M. Latif, Pacific thermocline bridge revisited, Geophys. Res. Lett., 26, 1329-1332, 1999b.

Seager, R., M. Blumenthal, and Y. Kushnir, An advective atmospheric mixed layer model for ocean modeling purposes: Global simulation of surface heat fluxes, J. Clim. 8, 1951-1964, 1995.

Tourre, Y. M., Y. Kushnir, and W. B. White, Evolution of interdecadal variability in sea level pressure, sea surface temperature, and upper ocean temperature over the Pacfic Ocean, J. Phys. Oceanogr., 29, 1528-1541, 1999.

Trenberth, K. E., and J. W. Hurrel, Decadal atmosphereocean variations in the Pacific, Clim. Dyn., 9, 303-319, 1994. 
Visbeck, M., J. Marshall, T. Haine and M. Spall, Specification of eddy transfer coefficients in coarse resolution ocean circulation models, J. Phys. Oceanogr., 27, 381-402, 1997.

Visbeck, M., H. Cullen, G. Krahmann, and N. Naik, An ocean model's response to North Atlantic oscillation-like wind forcing, Geophys. Res. Lett., 25, 4521-4524, 1998.

Wang, C., and R. H. Weisberg, Climate variability of the coupled tropical-extratropical system, Geophys. Res. Lett., 25, 3979-3982, 1998.

White, W. B., Design of a global observing system for gyre scale upper ocean temperature variability, Prog. Oceanogr., 36, 169-217, 1995.

Zhang, R. H., and Z. Liu, Decadal thermocline variability in the North Pacific Ocean: Two pathways around the subtropical gyre, J. Clim., 12, 3273-3296, 1999.

Zhang, R. H., L. M. Rothstein, and A. J. Busalacchi, Origin of upper-ocean warming and El Nino change on decadal time scales in the tropical Pacific Ocean, Nature, 391, 879-882, 1998.
Zhang, Y., J. M. Wallace, and D. S. Battisti, ENSO-like interdecadal variability: 1900-1993, J. Clim., 10, 1004$1020,1997$.

M. Cane, A. Karspeck, N. Naik, and M. Visbeck, LamontDoherty Earth Observatory of Columbia University, RT 9W, Palisades, NY 10964-8000. (cane@ldeo.columbia.edu; alicak@ldeo.columbia.edu; naik@ldeo.columbia.edu; visbeck@ldeo.columbia.edu)

W. Hazeleger, Oceanographic Research Department, Royal Netherlands Meteorological Institute, Postbus 201, 3730 AE De Bilt, The Netherlands. (hazelege@knmi.nl)

(Received July 10, 2000; revised November 17, 2000; accepted December 4, 2000.) 